\title{
MÁS ALLÁ DEL AMOR: CAUTIVERIO, SUBVERSIÓN Y SENTIDO DE SÍ EN LAS CARTAS DE AMOR DE NAHUI OLIN ${ }^{1}$
}

\section{BEYOND LOVE: CAPTIVITY, SUBVERSION, AND A SENSE OF SELF IN NAHUI OLIN'S LOVE LETTERS}

\author{
Lorena Garrido Donoso \\ Universidad de Playa Ancha de Ciencias de la Educación, Chile \\ lorena.garrido@upla.cl
}

\begin{abstract}
Resumen:
El objetivo de este ensayo es analizar parte de la correspondencia amorosa de Nahui Olin, artista y escritora que surge en el periodo de la posrevolución mexicana, época donde predominaba un discurso ambivalente con respecto a la mujer y su rol. Sostengo que Nahui Olin lleva al extremo varias convenciones de la carta de amor, no solo textuales sino también genérico-sexuales en lo relativo al rol pasivo que debe tener la mujer en la unión sexual. Hay en Nahui Olin un claro sentido de sí y de su situación como mujer dentro de esa visión ambigua, la que constituye un cautiverio del cual se libera creativamente mediante el ejercicio discursivo de expresar sin límites su yo íntimo; de manera que las cartas vienen a ser una extensión de sí misma y de su sexualidad.
\end{abstract}

Palabras clave: Nahui Olin, Carmen Mondragón, carta de amor, cautiverio, sentido de sí.

\begin{abstract}
:
The aim of this essay is to analyze part of the love correspondence of Nahui Olin, an artist and writer that emerged in the post-revolution Mexican period, a time when an ambivalent discourse regarding women and their role prevailed. I maintain that Nahui Olin takes to the extreme several conventions of the love letter, not only textual but also generic-sexual in relation to the passive role that women should have in the sexual union. There is in Nahui Olin a clear sense of herself and her situation as a woman within that ambiguous vision, which constitutes a captivity from which she creatively frees herself through the discursive exercise of expressing her intimate self without limits; so that the letters become an extension of herself and her sexuality.
\end{abstract}

Key words: Nahui Olin, Carmen Mondragón, captivity, sense of self.

Recibido: 16 de agosto de 2021

Aceptado: 16 de noviembre de 2021

\footnotetext{
${ }^{1}$ El artículo es parte del proyecto Fondecyt $\mathrm{N}^{\circ} 11190438$ "Subjetividad femenina e identidad cultural en la obra literaria y política de mujeres del México posrevolucionario (1920-1950)”.
} 
Artículo. Lorena Garrido Donoso. "Más allá del amor: cautiverio, subversión y sentido de sí en las cartas de amor de Nahui Olin"

La Revolución Mexicana significó un cambio en todos los ámbitos de la sociedad, incluido el aspecto de género, lo cual es lógico si consideramos que "las revoluciones derriban las bases de sistemas prevalecientes de autoridad e inadvertidamente debilitan los sistemas patriarcales que utiliza la mayoría de los regímenes para gobernar” (Kaplan 407). De hecho, ocurren en México variados acontecimientos que dan cuenta de un movimiento organizado de mujeres que luchan por sus derechos.

En 1919 se funda el Consejo Feminista Mexicano, 'para la emancipación política, económica o social de la mujer', que promueve la ayuda mutualista y publica una revista quincenal: La mujer. En 1920 se celebra un congreso de obreras campesinas; y en 1923 el primer congreso nacional feminista se reúne en la Ciudad de México con 110 delegadas y demandas feministas: búsqueda del voto, exigencia de una moral sexual que no discrimine, demanda de guarderías, comedores públicos, coeducación para las jóvenes protección a trabajadoras domésticas (Monsivais 30).

Por lo tanto, y tal como señala Mary Kay Vaughan,"la Revolución no fue solo un ataque contra la propiedad, la jerarquía social y la exclusión; fue una embestida contra la moral victoriana y las reglas de represión sexual, y llevó a las mujeres al espacio público en formas nunca antes vistas" (45). Esta irrupción en el espacio público, permeará todos los aspectos de la vida pública, como la literatura y el arte, aunque no estará exenta de contradicciones.

La posición ambivalente en que el proyecto revolucionario ubicaba a la mujer, es algo que varios autores registran. Así, esto se manifiesta en un discurso oficial en que se valora a la mujer y se la quiere instruir, pero al mismo tiempo se critica y rechaza el surgimiento de la "chica moderna": una mujer independiente, consumidora, atlética y de pelo corto, las "pelonas", que vienen a representar el libertinaje extranjero².

Jean Franco sostiene que la Revolución propició un "espíritu mesiánico que transformó a los hombres en superhombres y constituyó un discurso que asoció la virilidad con la transformación social de tal manera que marginó a las mujeres precisamente cuando en apariencia estaban en vías de liberación" (140). O dicho de otro modo, si bien se

\footnotetext{
${ }^{2}$ A este respecto es interesante el análisis que Joanne Hershfield hace de la imagen de esta nueva mujer en el contexto mexicano: "The Project was marked by a profound tension between the impetus to develop a homogeneus "Mexican" national identity and a compelling impulse to be modern within the trasnational sense of modernity" (6).
} 
evidencia que el discurso político posrevolucionario busca definir a México como una nación moderna, democrática e integradora, existe aún un fuerte control de la mujer, su cuerpo, su rol, como medio para asegurar la unidad del proyecto revolucionario (Blanco).

Desde la antropología, Marcela Lagarde nos habla del concepto de cautiverio: "las formas de ser mujer en esta sociedad y en sus culturas, constituyen cautiverios en los que sobreviven creativamente las mujeres en la opresión" (36). Luego agrega: "El cautiverio de las mujeres se expresa en la falta de libertad, concebida esta última como el protagonismo de los sujetos sociales en la historia, y de los particulares en la sociedad y en la cultura. En tanto cautiva, la mujer se encuentra privada de libertad" (37)

El objetivo de este ensayo es revisar y analizar parte de la correspondencia amorosa de Nahui Olin, artista y escritora que surge en esta época donde aún había una fuerte presencia masculina dominando el campo cultural. El porqué de la elección de revisar sus cartas se comprende si consideramos que el género epistolar es de gran valor no solo para conocer elementos biográficos de quien las escribe, sino también como un medio para comprender aspectos socioculturales del período y cómo las mujeres utilizan su escritura como puente entre el ámbito privado y el público. Aquí, la escritura además se manifiesta como una manera creativa de sobrevivir al cautiverio que le imponía un medio artístico y cultural dominado por el mesianismo. En ese sentido, Nahui Olin utiliza diversas expresiones artísticas (pintura, poesía, dibujo, ser modelo de artistas) como instancias para escapar de ese cautiverio impuesto, a la vez que logra definir y expresar su sentido de sí, definido por María Rubí Gómez como "la síntesis del cuerpo y el espíritu, como la capacidad discursiva de darse un sentido o descubrir ante sí misma y los otros su propia humanidad" (11).

Precisamente, "Nahui Olin representa la imagen evanescente de una crisis que era producto de la Revolución, y la promesa de una nueva feminidad que se construía bajo los influjos de a nueva formación cultural" (Gómez 120). Dicha feminidad se relaciona con una autoconciencia de ser objeto sexual (marcado por su impactante belleza), lo que si bien en un primer momento satisface su narcicismo, es demasiado superficial para su profundidad e inteligencia. Esto la lleva a continuar en la búsqueda de un camino que le permita expresarse y ser dueña de su destino, lo que queda expresado con claridad en la correspondencia que aquí se analiza. En específico, veremos en estas cartas una clara 
Artículo. Lorena Garrido Donoso. "Más allá del amor: cautiverio, subversión y sentido de sí en las cartas de amor de Nahui Olin"

conciencia de sí misma y las limitaciones dadas por la sociedad y el lenguaje patriarcal que no parecen detenerla.

Cabe señalar que el cautiverio al que me he referido anteriormente guarda estrecha relación en este caso con el concepto de amor como control, como medio de ejercer un poder, desarrollado en varios trabajos por Anna Jónnasdóttir. Desde un enfoque que ella denomina "sexualidad política", y que proviene de las premisas materialistas y sociales de Marx y su cruce con el feminismo, Jónnasdóttir nos habla de las "relaciones sociosexuales" que identifica como otro poder, además del económico, que permite el estudio de las sociedades y el cambio social. Ello basándose en la idea de que el amor y el poder del amor es "una capacidad humana creativa-productiva -y explotable- de importancia comparable a la del trabajo o a la del poder del trabajo" (248); hay, por lo tanto, una pérdida de control por parte de las mujeres en las relaciones de pareja al haber una "apropiación de los recursos sociosexuales de las mujeres por parte de los hombres" (255). Esta perspectiva nos permite observar con mayor claridad el grado de subversión de las relaciones de poder amorosas dentro de la correspondencia de Nahui Olin; donde observamos una conciencia de su situación y su intención de romper con los cautiverios que enfrentaban las mujeres no solo en lo público, sino también en lo íntimo.

Por todo lo anterior, mi hipótesis es que Nahui Olin lleva al extremo varias convenciones de la carta de amor, no solo genérico-sexuales en lo relativo al rol pasivo que debe tener la mujer en la unión sexual, particularmente en esa época, sino también a la relación que tradicionalmente se ha hecho de las mujeres con el género epistolar; es decir, el asociarlas con el polo de lo sensible y sentimental. Las cartas de Nahui Olin, precisamente están hechas sobre la base de una reescritura de las relaciones que se materializa en una voz que poco tiene que ver con la de una mujer como se entendía entonces, objeto de deseo, pasiva en la relación, en quien predomina lo sentimental. Aunque aún es posible identificar algunos tópicos que podrían ilustrar el cautiverio, estos son solo reflejo de la ambivalencia del rol de la mujer descrito más arriba y de la persistencia de algunos valores tradicionales que creo más bien corresponden a tópicos literarios utilizados por su autora. No olvidemos que las escritoras de profesión no abandonan su oficio de escritura cuando escriben sus cartas (Arriaga). Hay en Nahui Olin una clara conciencia de sí y de su situación como mujer dentro de ese mundo hipócrita y 
ambivalente, del cual intenta liberarse mediante el ejercicio discursivo de expresar libremente su yo íntimo, de manera que la carta viene a ser una extensión de sí misma y de su sexualidad.

Antes de revisar las cartas se hace necesario especificar algunos aspectos del género epistolar y, particularmente, de la carta de amor.

\section{El género epistolar y la carta de amor}

El texto epistolar hace ya un tiempo que ha ganado su lugar en el ámbito de los estudios literarios al presentarse como un género discursivo con características propias. Sus leyes de composición nacen de la característica primordial de su existencia: la carta es una escritura que se realiza en la ausencia de uno de los interlocutores. Este "diálogo diferido", como lo ha llamado Patrizia Violi, se caracteriza porque "la presencia real del uno tan solo puede acompañarse de la reconstrucción imaginaria del otro, en un tiempo y lugar distintos" (89). El resultado es un texto que exhibe una tensión entre la realidad concreta del acto de enunciación y del sujeto real- y su representación discursiva, "verdaderos simulacros de una realidad pasada por el filtro de un individuo" (Violi 89). Precisamente, atendiendo a ese "filtro personal" es que "desde la perspectiva del análisis del discurso resulta posible leer y reconstruir parcelas del pasado, más allá de la letra impresa, para descubrir un sistema ideológico que se manifiesta en ese diálogo en ausencia, representado por las cartas" (Hinde y Zandanel 14-15). De hecho, hay una relación estrecha entre el género epistolar y la subjetividad, ya que al ser un género menos mediatizado, escribir una misiva "es cobrar conciencia de nosotros y hasta el que escriba una carta a la ligera se pondrá delante del testimonio" (Salinas 35).

Es importante precisar que no es la intención de este trabajo tomar las cartas como documento fiel del pensamiento de su autora, sino, como se ha señalado, como fruto de su creatividad plasmada, como una representación de su identidad que revela sus deseos a partir de lo que se ha llamado "comentario autorreflexivo" (Doll, "La carta privada", 41). Como asevera con mucha razón Roxana Pagés-Rangel, "el sujeto de la escritura se construye para el lector; esto es, una identidad se re-presenta, mediante palabras o, a veces, mediante otro sistema de signos para el "otro" que a su vez nace del texto con-figurado por el deseo del escritor o la escritora. Casi como ningún otro medio de escritura, la carta habla 
Artículo. Lorena Garrido Donoso. "Más allá del amor: cautiverio, subversión y sentido de sí en las cartas de amor de Nahui Olin"

- y es en sí misma un producto - de los mecanismos de representación”. (5) En ese sentido, la representación que Nahui Olin hace de sí misma refleja una superación de los cautiverios que controlaron su vida por mucho tiempo, permitiendo expresar libremente su sexualidad, sus deseos y una conciencia de su ser corporal que intenta materializar a través de las palabras. En ese sentido, su escritura no obedece solo a la intención de mantener la relación amorosa, como ocurre generalmente con la carta de amor, sino también, y desde la perspectiva feminista, se transforma en un espacio de subversión, algo que ha ocurrido históricamente con los textos de la carta de amor que "han funcionado como sitio estratégico desde el cual las mujeres han tomado la palabra, especialmente en épocas en que emprender la escritura en los géneros llamados 'mayores' era una cuestionada transgresión, si no una imposibilidad" (Doll, "Las cartas de amor de Gabriela Mistral", $155)^{3}$.

La particularidad de estas cartas es que Nahui Olin lleva esta transgresión a otro ámbito en el que tensiona los límites textuales, lingüísticos y sociales del “deber ser” de una mujer de su tiempo.

\section{Contexto de las cartas de Nahui Olin}

Nahui Olin, fue pintora, caricaturista, pianista, poeta, modelo de pintores y fotógrafos. Los documentos de la época, libros, cartas, artículos periodísticos, pinturas y fotos nos la presentan como una mujer que formó parte activa del circuito cultural de lo años 20 y 30 en México, pero, sin embargo, sufrió en vida la falta de reconocimiento, el olvido y luego la desaparición total como figura artística e intelectual por muchos años, hasta que Tomás Zurián diera con sus fotos y comenzara a desempolvar su vida y obra. Las razones de esta exclusión y olvido obedecen al mito que se creó de ella, el que terminó por silenciar su obra: el de la femme fatale, la mujer loca, la ninfómana. Quizás haya que situar a la artista dentro de un contexto de pares mujeres, porque en México en aquella época había muchas mujeres rupturistas.

\footnotetext{
${ }^{3}$ Así también lo consigna Meri Torres (2001) en su estudio de las cartas escritas por mujeres desde las salonnières francesas del s. XVIII, quienes utilizaban la correspondencia de manera consciente como un medio para burlar las restricciones de publicación que afectaban a las mujeres.
} 
Nahui Olin cumple con una doble transgresión: el como mujer irrumpir con una obra diferente que no calzaba con los discursos que dominaban la sociedad posrevolucionaria, por una parte, y por otra, el ejercer libremente su sexualidad. Como afirma Poniatowska, “fue quizá la primera que se aceptó como mujer-cuerpo, mujercántaro, mujer vasija. Poderosa por libre, se derramó a sí misma, sin muros de contención” (32).

Nahui Olin nace como Carmen Mondragón en 1893, en el seno de una familia acomodada, lo que la ayudó en sus comienzos a obtener el capital cultural suficiente para moverse desde joven dentro de un circuito artístico y cultural que sobrepasa las fronteras de México.

Su padre, el general Mondragón fue un militar que durante el profiriato diseñó un arma que lleva su nombre lo que lo llevó a vivir a París con su familia desde 1897 a 1903, es decir cuando Carmen tenía entre cuatro y diez años. Cuando vuelven a México ella continúa con su educación en francés como lo hacía la elite de esa época y escribe sus primeros poemas en dicha lengua, en un cuaderno que recupera años más tarde y que publica en 1924 con el nombre de Á diez ans sur mon pupitre, donde su revela no solo su dominio en el idioma, sino una sensibilidad y lucidez pasmosa para una niña de esa edad. Así dice en "Incomprendida":

... no soy feliz porque la vida no ha sido hecha para mí, porque soy una llama devorada por sí misma y que nada puede apagarla, porque no he vivido con libertad la vida privándome de los derechos a saborear y a ser vendida, como las esclavas en otros tiempos, a un marido. Protesto, a pesar de mi edad, por quien está bajo la tutela de los padres.

-Pero ¿para qué ser comprensiva, tanto, si se me obliga a vivir primero bajo la tutela rigurosa de mis padres y luego la de un marido? Así la mujer se convierte en un problema social bien resuelto para la conveniencia de los gobiernos y de las costumbres. -

(En Rosas 162)

Como vemos, ya a los diez años tiene claridad de la situación de subordinación en que las mujeres se ven atrapadas desde nacer, y, sin embargo, las presiones sociales la llevan a casarse muy joven con Manuel Rodríguez Lozano, en ese momento estudiante en el colegio militar. 
Artículo. Lorena Garrido Donoso. "Más allá del amor: cautiverio, subversión y sentido de sí en las cartas de amor de Nahui Olin”

Este hecho de ir en contra de sus propias convicciones no debiera extrañarnos ya que el propio Bourdieu advierte que "los dominados o dominadas interiorizan su propia dominación y terminan así por dirigir ellos o ellas misma su opresión" (Ramallo 139), de hecho, Adriana Malvido cuenta que Carmen decide no casarse tres días antes del matrimonio, pero finalmente cede ante la amenaza de su madre de enviarla a un convento.

Luego de unos años en Europa, Carmen vuelve con su marido a México en 1921, cuando hay una efervescencia cultural liderada José Vasconcelos como secretario de educación, y comienza a frecuentar los salones y las exposiciones de pintura, llegando a participar en una exposición colectiva llevada a cabo en la Escuela Nacional de Bellas Artes en 1921. Al poco tiempo conoce a Gerardo Murillo, alias el Dr. Atl, poeta, profesor de arte, activista y vulcanólogo, que cuando conoce a Carmen, se enamora perdidamente. Ella le corresponde y abandona a su marido al poco tiempo, para vivir con Atl, quien la bautiza como Nahui Olin, fecha del calendario azteca que significa el movimiento renovador de los ciclos del cosmos.

Carmen pasa a ser Nahui, y como ella, ejerce la libertad que el tiempo como miembro de la familia Mondragón no le permitió. Nunca más aceptó que la llamaran Carmen.

La relación con Atl va a ser significativa no solo en lo emocional, sino que también en lo artístico ya que él le enseña su técnica de pintura y la anima a publicar sus escritos. De esa relación aún perviven más de doscientas cartas escritas por Nahui y varios retratos que el Dr. Atl le realiza.

\section{Las cartas de Nahui Olin al Dr. Atl}

Primero me quiero referir a la forma en que estas cartas fueron presentadas al público lector, que obedece una situación de enunciación bastante particular. A diferencia de lo que suele ocurrir con este tipo de documentos, esta correspondencia no fue publicada póstumamente ni tampoco como tal. Es el propio destinatario de estas cartas, el Dr. Atl, quien lo hace, lo que a simple vista pareciera constituir una falta al principio de confidencialidad que debe haber en toda correspondencia. No obstante, las cartas parecen como parte de una narración ficcional: Gentes profanas en el convento (1950), obra que 
combina la autobiografía, el ensayo y la ficción, o como precisa José Emilio Pacheco: una "novela sin ficción" ("Las cartas de Nahui Olin", 50).

En estas páginas, Atl relata diversos acontecimientos y, entre ellos, una intensa historia de amor encontrada en una tumba del claustro de La Merced. Se recrea aquí la relación de Eugenia y Pierre (Nahui y el propio Atl) y se reproduce una parte de las cartas que Nahui le enviara durante el período que va desde 1921 a 1925. Por lo tanto, nuestra lectura de esas cartas no es directa; está mediatizada por este narrador que nos las presenta, comenta y opina, haciendo que las leamos como obra de ficción. Las razones de esta ficcionalización podrían estar en lo que señala José Emilio Pacheco: "La insólita descripción de sus relaciones era tan fuerte para 1950 que Atl la enmascaró como una historia del siglo XIX: las cartas de una muerta que él encuentra en un sepulcro del Convento de La Merced.” (“Carmen Mondragón...”, 51)

Celia Fernández nos dice, con respecto a la carta de amor, que el yo epistolar, situado en el presente, es un personaje de sus narraciones (20). El yo de la carta es ficcional, es una construcción verbal así como el destinatario. De esta forma, el yo ya ficcionalizado por Nahui al escribir sus mensajes está siendo doblemente ficcionalizado por este narrador que es quien supuestamente encuentra las cartas en el convento, que además nos suplanta como lectores, al ser él quien efectúa el proceso de contextualización que normalmente debe realizar el lector epistolar. Atl se transforma así en un editor de estas cartas:

El editor se constituye en guía de los lectores y facilitador de la lectura del epistolario; llena vacíos (identifica nombres, lugares, obras), corrige errores ortográficos, añade datos históricos, elimina secciones, aclara palabras. La labor editorial se concibe como la fuerza unificadora de unos 'pliegos sueltos'. (Pagés-Rangel 34)

Tenemos así un relato dentro del relato que refuerza la ficcionalidad de la carta de amor de la que hablaba Celia Fernández, a la vez que nos permite distanciarnos aún más del contenido explosivo de las misivas, pero que nos lleva también a dudar sobre aspectos de la historia aquí narrada, especialmente de la descripción que como editor, Atl hace de Eugenia/Nahui. 
Artículo. Lorena Garrido Donoso. "Más allá del amor: cautiverio, subversión y sentido de sí en las cartas de amor de Nahui Olin"

La Nahui mostrada por Atl a través de sus comentarios a las cartas y de los comentarios de Pierre, es una mujer a la que le reconoce su belleza, talento y sobre todo, su inteligencia, pero que, sin embargo, aparece como una vampira que succiona a Pierre (Atl), el cual es una víctima de sus encantos y pasiones. Cuando describe el día que Pierre conoce a Eugenia, luego de referirse en detalle a los atributos físicos de ella, exclama: “Pobre de mí!”. (86)

Por citar otro ejemplo, en un pasaje donde Pierre se refiere a que imagina a Eugenia de niña: “Aquella chiquilla tenía los mismos ojos de fiera apocalíptica que yo estaba contemplando en su maravillosa realidad. Cuando levantó la cabeza y los asomó entre las guedejas de oro de su pelo, tuve un sacudimiento de terror"(117). En otro pasaje cuenta, que en respuesta a un ataque de celos, ella lo despierta en la noche: "Eugenia estaba sobre mí, desnuda, con su cabellera revuelta sobre mi cuerpo, empuñando un revolver cuyo cañón se apoyaba en mi pecho" (119).

De alguna manera, Atl, a través de Pierre, predispone al lector de las cartas a ver a Nahui como una femme fatale, enloquecida de pasión; mujer predadora que deja a Pierre en una situación de víctima, a merced del comportamiento posesivo y errático de Eugenia. En este sentido, vemos en el discurso de Atl la ambivalencia de criterios de ese México en renovación, ya que critica la hipocresía de la gente de su tiempo, pero él mismo reproduce los estereotipos femeninos que dominaban aún en el imaginario cultural de la época. Siguiendo a Pagés-Rangel: "El movimiento de lo privado a lo público, este proceso de traslación [hecha por el editor]... aparece marcado por premisas ideológicas, que reflejan, al tiempo que reflexionan sobre ellas, las prácticas institucionales y literarias de cada momento histórico" (34-35).

Esto contrasta con la mujer que escribe las cartas y que se muestra enamorada y en ningún caso como alguien que intenta destruir a su amante a través de su poder de seducción. Al contrario, vemos en una de las primeras cartas que le escribe, poco después de conocerlo, una actitud opuesta:

Mi amor es extraño y a veces me ocasiona terror- ¿por qué terror?- porque temo quemarme en la propia llama de mi amor. Pero no te alejes de mí, amor mío- porque solo cerca de ti existe el único placer y el único consuelo que necesita ésta complicada amada que sólo puede saludarte al 
pasar frente a ti y desvanecerse como un asombra- una sombra que tú amas. (87-88)

Nahui Olin tiene también miedo, pero no de él, sino de su propia pasión, la misma que pone en cada cosa que hace. En lugar de intentar seducir a quien la viene recién conociendo, le advierte que es una persona "complicada". No oculta su personalidad ni su manera de ser, de la que tiene completa consciencia. Es más, le pide que no se aleje. ¿Qué la lleva a auto describirse como "complicada"? Creo que tiene más bien relación con lo que dicen de ella. Y ella lo acepta porque se sabe diferente y, como veremos más adelante, se siente orgullosa de ello, por eso no lo oculta a su futuro amante. También está en una situación complicada al estar casada con Rodríguez Lozano y ser prisionera de los chantajes familiares y las habladurías, algo que finalmente deja de importarle porque se interpone a sus deseos.

Otra característica del género epistolar que se ve de alguna manera alterada en esta correspondencia es que, normalmente, el emisor las escribe a partir de una distancia física y temporal del destinatario, es por ello que intenta así recuperar la ausencia del ser amado; sin embargo, el gran cuerpo de estas epístolas (sin incluir la ya citada) corresponde a escritos realizados por Nahui Olin en presencia de Atl, en su propia casa, poco después de haber terminado el acto sexual. Ella sale a la terraza y le escribe una carta cada vez. ¿Qué sentido tendrá hacerlo si no hay ausencia ni distancia que salvar? La respuesta a esta pregunta se cruza con un aspecto que se relaciona directamente con el planteamiento de la subjetividad de su autora, ya que en la carta privada se produce un espacio donde el sujeto puede construirse permanentemente, "es la puesta en escena de un proyecto siempre inconcluso, de un yo siempre haciéndose, y, al mismo tiempo, proyecto de discurso que espera la respuesta/confirmación del discurso ajeno" (Doll, "La publicación de cartas privadas", 176). Nahui Olin establece en estas cartas un sentido de sí, es decir, aprovecha este espacio para expresar abiertamente su ser, su visión del amor, del sexo, del amante y de su rol como mujer dentro de esta relación y aprovecha la instancia de recibir esa confirmación al ver la reacción de Atl al leerlas.

Ese "yo" que aparece representado en estas cartas, se entrega a su amor en cuerpo y alma, así escribe en una de ellas: 
Artículo. Lorena Garrido Donoso. "Más allá del amor: cautiverio, subversión y sentido de sí en las cartas de amor de Nahui Olin"

Mi amor es ya una locura que me lleva a la muerte.

Desgarra mi pecho, enflaquecido por tu amor y ábreme el corazón para que mires el espíritu de mi pasión.

Toda su sangre se ha solidificado, es un rubí, una piedra roja-roja de dolor, rojo es su color-rojo de sangre de una herida que no cicatrizará jamás.

Mírate en esa sangre y su reflejo también te volverá rojo a ti.

Y subirás de sus vapores como una nube iluminada por el crepúsculo.

Como la nube que sale del cráter de un volcán en la oscuridad de la noche. Roja, roja.

Todo el universo es rojo porque lo ha inundado de sangre mi pasión. Mis ojos verdes fulguran entre el incendio.

Relámpagos de otros mundos.

Te pertenezco hasta la última partícula de mi carne. (90)

Este fragmento refleja precisamente la idea de la compenetración absoluta entre los amantes unidos por la sangre que es pasión, dolor, herida, cráter, que termina con la declaración de que es una de entrega física total. Esa entrega se transforma en adoración al amante como a un dios, ante quien entrega su propia cabeza como sacrificio:

Te amo, te amo, desesperadamente, lujuriosamente, misteriosamente, como la vida, como la muerte.

¡Oh amor, amor divino! Te ofrezco mi cabeza para que sirva de cascabel a tus pies o de escalón a tu gloria.

Eres Dios-ámame como Dios- ámame como todos los dioses juntos, no, ámame como tú sabes amar. (91)

Podemos observar en este fragmento una situación que podría ser entendida como reflejo del cautiverio típico de la mujer en la relación amorosa. Ella lo adora como a un dios y le otorga a él el poder de hacer con ella (su cabeza) lo que quiera. Sin embargo, al continuar la lectura vemos que esa aparente sumisión da un giro:

perfora con tu falo mi carne -perfora mis entrañas- desbarata todo mi serbebe toda mi sangre y con la última gota que me quede yo escribiré esta palabra: te amo, y cuando esa sangre se haya secado, gritaré: te amo.

Haz pedazos mi corazón -juega con él como un niño con un muñecorásgalo sin piedad, ¡oh, divino amor!

Ama mi grandeza

Ama mi dolor

Ama mi amor. (91) 
Lo primero que salta a la vista es que la escritura de ese yo, no se acerca a la típica voz femenina de la carta de amor. La entrega total y la exhortación directa al amado corresponden más bien al discurso de un amante masculino. Como afirma José Emilio Pacheco, "Carmen Mondragón toma por asalto un vocabulario que durante un siglo los hombres habían monopolizado para dirigirse a las mujeres" ("Las cartas de Nahui Olin" 51). Además, lejos de minimizar su existencia ante el amado, se valora lo suficiente para hablar de su propia grandeza.

De esta forma, Nahui Olin no tiene problemas en reconocer la lujuria de su pasión:

Te he amado tanto el calor del lecho y gozado tu carne- y me has envuelto tantas veces en tus caricias y tan fieramente se ha derramado sobre ti mi lujuria inextinguible- que pienso muchas veces si cada goce no será el último.

Eres una cosa humana- tan real y constante que no puedo pedir más- que no puedo sentir más-que toda yo no soy ya tuya ni tú mío-

Y que no existimos- pero a veces siento como si yo fuera el átomo de una nebulosa y tú el Universo que la contiene- y mi imaginación se dilata hasta el más allá de los últimos límites del deseo- y de repente se contrae en mi sexo, que a su vez se agranda como un abismo sideral. (92)

Pese a lo directo de sus declaraciones, Nahui Olin tiene un discurso que sí se aparta del poeta hombre cantándole a su musa, porque a diferencia del discurso patriarcal que ve a al amante como un ser supra terrenal o como simplemente un objeto, Nahui Olin ve a su amante como un ser humano, terreno, y eso es lo que ella valora y le hace amarlo; no obstante, pese a esta realidad que reconoce y dice valorar, la propia hablante le confiere a su escrito un grado ficcional, ya que tiene claro que es producto de su imaginación . Nahui juega con ambos grados de enunciación, consciente de escribir un texto que sobrepasa los límites discursivos y género-sexuales, aceptando la libertad de cada uno (el no ser propiedad del otro) y el ver su amor como algo más grande que ellos mismos.

El propio Atl, escondido tras el narrador que a su vez lee a su alter ego, Pierre, dice que este anotó en el reverso de la carta que acabo de citar:

¡Carta desorbitada! Pasión que no se conforma con los paroxismos de la carne, con la lujuria que se revuelca en el lecho: necesita más desahogo, gritar, escribir, escribir fuera de la vida después de haberse saciado de 
Artículo. Lorena Garrido Donoso. "Más allá del amor: cautiverio, subversión y sentido de sí en las cartas de amor de Nahui Olin"

todo lo que la carne puede dar, escribir, desorbitadamente como si viviera en otros mundos. (93)

Aquí el Dr. Atl/narrador/ Pierre da en el blanco de lo que significan para Nahui Olin estas cartas: creo que es un intento de extender al acto amatorio más allá de lo posible, llevarlo a otra dimensión casi sideral, para lo que se vale del mundo narrado creado en ellas, que por lo demás transgreden otra característica que les es propia: la búsqueda de una respuesta. Escribir estas cartas luego del encuentro sexual le permite a Nahui revivirlo y observar la reacción de su destinatario a quien ella ve, revivir el acto. Tal vez esto sea una característica de Nahui en todo, su deseo por empaparse de cada emoción, de cada experiencia y sentirla hasta el final. Ese grado de intensidad estaría también reflejado en su poesía y ya se dejaba ver en sus escritos de 10 años: "la vida no ha sido hecha para mí... Soy una llama devorada por sí misma”.

El amor al que aspira la autora de estas cartas es completo. Es físico, pero también intelectual, así lo sostiene en otra carta:

En mis brazos, en mi pensamiento Inflamas mi cerebro como inflamas mi corazón.

Te amo después de amarte y a veces te amo dentro de mí misma como si no existieras, mientras nuestras carnes son un solo cuerpo, una sola intención, un solo deseo.

A veces todo mi cerebro está en mi sexo y a veces todo mi sexo está en el cerebro. (93-94)

Su cerebro crea y recrea el encuentro sexual que viene a ser una comunión total entre los amantes. El sujeto real inasible es una especie de distanciamiento en Nahui que le permite tener mayor consciencia de lo evocado. La escritura epistolar produce un efecto de inmediatez, que es efectiva en el caso de estas cartas. La subjetividad que ella expresa es completa, ya que se percibe como cuerpo y cerebro, como una simbiosis de ambas partes que funcionan unidas y que la componen haciéndola un ser integral. De hecho, destaca que el amor que siente por Atl es también intelectual: va de a mano con la admiración que siente por él y en su capacidad de satisfacer también a su intelecto. Está en sus brazos y en su pensamiento. Está en toda ella.

Por último, me referiré brevemente a la última carta que ella escribe, cuando la relación está terminada, y que por esta razón, sí envía por correo: 
Vivimos encerrados en una cárcel, el universo infinito, pero odioso.

Hechos de origen desconocido pesan sobre nuestra voluntad y nos doblegan. Pero mi amor fermenta y me produce una embriaguez que me consume en medio de torturas extrañas y levanto mi cabeza sobre el mar de las dificultades y de la mediocridad para amarte soberanamente como te amé ayer, como te amo hoy, como te amaré siempre, aun después de que muramos. (132)

Hay en esta despedida una claridad respecto de sentirse cautiva, prisionera en un mundo que no está preparado para su intensidad y que califica de "odioso" y "mediocre", pero donde a pesar de eso "levanta la cabeza".

Vemos en estas cartas a una mujer que, aunque consciente de los límites establecidos para su género, vive sin embargo, la vida que ella elige, sin importarle las habladurías, expresando su pasión con libertad, en una relación donde ella toma las riendas y ejerce su poder de seducción sobre Atl. Rompe así con otro tabú histórico para la mujer que es lo que Jónnasdóttir llama “acceso al éxtasis”, cuya práctica aparece como prohibida, ya que la posiciona como "una persona sexual con dirección y seguridad propias" (265), lo que le finalmente le valió la traición de Atl y la espalda de una sociedad que por mucho tiempo la despreció calificándola de "loca". Confirma también, que lejos de ser una femme fatale, es una mujer que ama a Atl más allá del tiempo y la distancia.

Nahui Olin transgredió los roles reservados para las mujeres del México posrevolucionario no solo a través de su poesía, sus pinturas, sus desnudos fotográficos (que tanto escandalizaron en la época y lo volvieron a hacer cuando fueron redescubiertos por Tomás Zurián en los 90), sino que también con su vida amorosa de la que toma las riendas abandonando a Manuel Rodríguez Lozano, no siendo madre, siendo amante de Atl y luego de otros hombres: romances que quedan registrados en su obra pictórica, que fue calificada como "naïve". Nahui Olin también transgrede las convenciones de la carta privada de amor, dejando en claro la autenticidad y claro sentido de sí que le permite pararse en sus pies frente al mundo, segura de sí misma, de lo que quiere, de lo que provoca, sin medir las consecuencias que implicaban romper con los cautiverios que se le imponían. 
Artículo. Lorena Garrido Donoso. "Más allá del amor: cautiverio, subversión y sentido de sí en las cartas de amor de Nahui Olin"

\section{Observaciones finales}

Como hemos visto a lo largo de este ensayo, el lugar de la mujer dentro del proyecto del México posrevolucionario era ambivalente. Junto con el surgimiento de un movimiento de mujeres que luchan por la igualdad de derechos ante la ley, se realizan una serie de cambios que apuntan a su formación e inclusión en dicho proyecto. No obstante, hay claras contradicciones que se originan en un choque entre, por un lado, un intento por resguardar las tradiciones culturales de lo propiamente mexicano y, por otro, el esfuerzo por hacer de México una nación moderna.

De lo anterior se deduce que hay un discurso y una imagen de mujer proveniente principalmente de Estados Unidos, la "chica moderna”, apoyado por la publicidad y el cine, y que se contradice con una visión mesiánica de la nueva nación Mexicana. Esta ambivalencia dará espacio a que las mujeres irrumpan en el campo cultural mexicano no sin dificultades.

En este trabajo quise observar algo de dichas contradicciones y las diversas formas de cautiverio que artistas como Nahui Olin experimentaron, revisando parte de su correspondencia amorosa para observar, más allá de los rasgos biográficos, elementos discursivos que nos permiten observar una ruptura con varios de los preceptos propios del género epistolar y de la carta de amor, lo que es a su vez reflejo de la subversión que ella hace también en su vida.

La carta la vemos como un espacio creativo que les permite superar ciertos cautiverios propios de las mujeres: el tener que probar que son artistas en sí mismas, el matrimonio y todas sus restricciones, especialmente las que rigen las relaciones sociosexuales; la apropiación y manejo de sus cuerpos y de un discurso que prueba su conciencia de ellos (sentido de sí).

Nahui Olin era la pelona, o la flapper: de cabello muy corto, vestidos cortos, o incluso ninguno, dado los desnudos que hizo para fotógrafos y pintores. Completamente segura de su belleza y del poder que ejercía con ella, vivió una vida llena de críticas que la llevaron incluso a ser rechazada por su familia y morir en la soledad junto a la única compañía de sus gatos. Ejerció su sexualidad libremente, la plasmó de manera abierta en sus pinturas y lo vemos también en la escritura de sus cartas donde el lenguaje utilizado era 
abiertamente erótico, de una sujeto deseante que no temía expresar sus más íntimos deseos. Por supuesto, ella lo hacía desde el ámbito privado de la carta, cuya confidencialidad fue traicionada por su amante-destinatario que se transforma luego en editor de las misivas.

Nahui Olin es completamente libre en sus cartas, las que sostengo, cumplen la función de extender los efectos del acto sexual recién realizado y hacer que el amante también los reviva, sin esperar respuesta, ya que el contexto de escritura de esas cartas es en su mayoría, delante del propio destinatario. La escritura es la extensión de su cuerpo y de las sensaciones y sentimientos que experimenta a través de él, rompiendo así con el tabú que implica el "acceso al éxtasis" utilizando un lenguaje que ha sido tradicionalmente masculino.

Estas pequeñas muestras textuales, creo que nos sirven para asomarnos a una visión de lo que implicaba ser mujer y artista en el México de la posrevolución, y que el arte en todas sus manifestaciones era una forma de liberarse de los cautiverios impuestos por la sociedad en la que les tocó vivir, siendo uno de los tantos medios o recursos para poder sortear las dificultades en un mundo donde aún las mujeres debemos pagar altos costos por romper con los modelos heteropatriarcales.

\section{Referencias}

Arriaga Flórez, Mercedes. "Epistolarios en Italia: un Punto de Vista Teórico Sobre un Género Femenino". Epistola I Literatura: Epistolaris, la Carta: Estratègies Literàries. Denes, 2005, pp. 69-78

Blanco Cano, Rosana. Cuerpos disidentes del México imaginado: Cultura, género, etnia y nación más allá del proyecto revolucionario. Iberoamericana, 2010.

Doll, Darcie. "Las cartas de amor de Gabriela Mistral o el discurso amoroso de una sujeto en fuga". Modernidad en otro tono: Escritura de mujeres latinoamericanas: 19201950. Cuarto Propio, 2004, pp. 153-172

---. "La carta privada como práctica discursiva. Algunos rasgos característicos". Revista Signos. vol. 35, núm. 51-52, 2002, pp. 33-57

Dr. Atl. Gentes profanas en el convento. Segunda edición. México, Senado de la República, 2003.

Fernández Prieto, Celia. “Apuntes para una teoría de la carta de amor”. Boletín de la Unidad de Estudios Biográficos, núm. 5, 2001, pp. 19-31.

Franco, Jean. Las conspiradoras: la representación de la mujer en México. Versión actualizada. Fondo de Cultura Económica, 2014.

Gintze, Gloria y María Antonia Zandanel. "Algunas nociones sobre el género epistolar a propósito de las cartas de Francisco Romero”. Cuyo. Anuario de filosofía argentina y americana, vol. 29, 2012, pp. 13-33. 
Artículo. Lorena Garrido Donoso. "Más allá del amor: cautiverio, subversión y sentido de sí en las cartas de

Gómez Campos, Rubí de María. El sentido de sí: un ensayo sobre el feminismo y la filosofía de la cultura en México. Siglo XXI, 2014.

Hershfield, Joanne. Imagining la Chica Moderna: Women, Nation, and Visual Culture in Mexico, 1917-1936. Duke University Press, 2008.

Jónnasdóttir, Anna G. “¿Qué clase de poder es 'el poder del amor’?”. Sociológica, núm. 74, 2011, pp. 247-273

Kaplan, Telma. "Género, caos y autoridad en tiempos revolucionarios". Género, poder y política en el México posrevolucionario, edición de Gabriela Cano, Mary Kay Vaughan y Jocelyn Olcott. Fondo de Cultura Económica, 2009, pp. 407-432

Lagarde, Marcela. Los cautiverios de las mujeres: madresposas, monjas, putas, presas y locas. Universidad Nacional Autónoma de México, 2005.

Malvido, Adriana. Nahui Olin: La mujer del sol. Circe, 2002.

Monsivais, Carlos. "Prólogo: De cuando los símbolos no dejaban ver el género (las mujeres y la Revolución mexicana)". Género, poder y política en el México posrevolucionario, edición de Gabriela Cano, Mary Kay Vaughan y Jocelyn Olcott. Fondo de Cultura Económica, 2009, pp. 11-37

Pacheco, José Emilio. "Carmen Mondragón (1893-1978). Más que tuya, Nahui Olin", Proceso, Cultura, núm. 851, 22 de febrero de 1993, pp. 50-51.

---. "Las cartas de Nahui Olin", Proceso, [México], 1 de marzo de 1993, pp. 52-53.

Pagés-Rangel, Roxana. Del dominio público: itinerarios de la carta privada. Ediciones Rodopi Bv, 1997.

Poniatowska, Elena. Las siete cabritas. Ediciones Era, 2012.

Ramallo, Urimare. "Supuestos y realidades de las relaciones de género en la cotidianidad. Reflexiones desde la mirada de Pierre Bourdieu." Fermentum. Revista Venezolana de Sociología y Antropología, vol. 21, núm. 60, enero-abril de 2011, pp. 134-148.

Rosas Lopátegui, Patricia. Nahui Olin. Sin principio ni fin: Vida, obra y varia invención. Universidad Autónoma de Nuevo León, 2011.

Salinas, Pedro. "Defensa de la carta misiva y de la correspondencia epistolar". Ensayos completos, tomo II. Taurus, 1981, pp. 220-293

Torras Francès, Meri. Tomando cartas en el asunto: las amistades peligrosas de las mujeres con el género epistolar. Prensas Universitarias de Zaragoza, 2001.

Vaughan, Mary Key. "Pancho Villa, las hijas de María y la mujer moderna: el género en la larga Revolución Méxicana". Género, poder y política en el México posrevolucionario, edición de Gabriela Cano, Mary Kay Vaughan y Jocelyn Olcott. Fondo de Cultura Económica, 2009, pp. 39-57.

Violi, Patrizia. "La intimidad de la ausencia: formas de la estructura epistolar". Revista de Occidente, núm. 68, 1987, pp. 87-99. 